\title{
3D containment modeling of PWR-KWU Trillo NPP with the GOTHIC code
}

\author{
Kevin Fernández-Cosials ${ }^{a}$, Samanta Estévez-Albuja ${ }^{a}$, Gonzalo Jiménez ${ }^{a, *}$, Rafael Bocanegra ${ }^{\text {a }}$, \\ Carlos Vázquez-Rodríguez ${ }^{\mathrm{a}}$, Luis Rey ${ }^{\mathrm{b}}$, Juan Carlos Martínez-Murillo ${ }^{\mathrm{c}}$ \\ a Universidad Politécnica de Madrid, Avda. de Ramiro de Maeztu, 7, 28040 Madrid, Spain \\ ${ }^{\mathrm{b}}$ Iberdrola Generación Nuclear, Madrid, Spain \\ ${ }^{\mathrm{C}}$ Centrales Nucleares Almaraz-Trillo, AIE, Madrid, Spain
}

\section{A R T I C L E I N F O}

\section{Article history:}

Received 27 November 2018

Received in revised form 17 May 2019

Accepted 21 May 2019

Available online 31 May 2019

Keywords:

Containment safety analysis

GOTHIC

CFD

KWU

3D models

\begin{abstract}
A B S T R A C T
Containment safety analysis is a field in expansion given the complex phenomenology developed during an accident, and the recent code capabilities improvement. In this paper, a modeling strategy to create complex containments with porous CFDs in a single control volume is presented. This methodology involves using solely Computer Aided Design (CAD) tools, to manage the geometrical model, instead of using the GOTHIC code pre-processor interface.

This methodology is applied to Trillo NPP (KWU 3 loops) where a LBLOCA is simulated to illustrate its capabilities. The results are compared against a Lumped Parameters model obtaining similar average values. Finally, a sensitivity analysis is made to quantify the influence of the modeling simplifications showing a small dependence. This implies that this modeling strategy is able to recreate models accurately, with an affordable computational cost, and with a time saving improvement, which nowadays is the main bottleneck for 3D containment models.
\end{abstract}

(ㄷ) 2019 Elsevier Ltd. All rights reserved.

\section{Introduction}

Nuclear safety and computational tools have been linked fields since the nuclear reactors first designs. Evolution in Nuclear Power Plants (NPPs) design and licensing came together with the development of nuclear computer codes to satisfy the industry and regulatory needs. As an example, system codes, such as RELAP, rely on a constant improvement since the 60's; from a lack of understanding of some accidental phenomena in RELAP-1, passing through the validation against experiments and including new features to finally be able to cope with a wide range of phenomena in NPPs transient analysis in the current version, (Mesina, 2016).

Regarding computational modeling of a NPP containment, those codes evolution has followed a similar path, being an essential tool since the beginning of the commercial NPPs design. CONTEMPT-LT was one of the first containment codes to appear, (Hargroves et al., 1979), and it was used to predict the long-term behavior after a Design Basis Accident (DBA) in a Pressurized Water Reactor (PWR) containment. To deal with the problematic faced in the containment during an accident, such as the large volume, the large

\footnotetext{
* Corresponding author.

E-mail address: gonzalo.jimenez@upm.es (G. Jiménez).
}

Mass and Energy (M\&E) release, the different species, phases and phenomena such as condensation, or flashing, the Lumped Parameters (LP) approach was used. This approach models the containment in just one or few nodes, which implies using several assumptions such as instantaneous mixing of the fluid, neglecting 2D/3D effects, or instantaneous interaction of all thermal structures with the fluid inside a Control Volume (CV), (Ofstun et al., 2013).

Besides these assumptions, LP models proved to be successful in calculating average values for pressure and temperature during a transient, as has been shown in several benchmarks and qualification exercises, (OECD/NEA, 2012). Different codes such as FATHOMS, MELCOR, or MAAP appeared over time, all of them using the LP framework to model the containment and performing accurately in calculating the average pressure and temperature in containment during a transient, (Chiang et al., 2017; FernandezMoguel and Birchley, 2015; Šadek et al., 2017). Recent codes such as ATHROC, (Chen et al., 2018) or CAP (Hong et al., 2015) still follow this same trend in the LP approach.

Even though the accuracy achieved with LP Models (LPMs) when analyzing pressure and temperature after a DBA or Severe Accidents (SA) is satisfactory for licensing purposes, improvements continued and during the last decade, and a major step was 
achieved with the capability of containment codes to solve the conservation equations in three dimensions. As an example, studies such as (Royl et al., 2000) or (Kim et al., 2004), which employed a 3D model, showed that phenomena like hydrogen transport is influenced by three-dimensional patterns and streamlines that cannot be modeled with a LPM. Similar discussions are shown in the work by Jimenez et al, where local temperatures observed in 3D models, are found to be higher than the licensing limit calculated with LPMs, (Jimenez et al., 2017). Thus, 3D containment models appeared as a valuable tool for nuclear safety analysis.

The extra information that can be obtained with a 3D model relative to a LPM is not the only benefit. LPMs have inherent assumptions, as commented before, and these assumptions can modify the solution in an inaccurate manner, making impossible to simulate accurately certain phenomena, (OECD/NEA, 2014). These problems caused by these assumptions can be partially solved with 3D models.

However, 3D simulations performed with containment codes come with a strong drawback: the time needed to implement the geometry and develop the computational mesh. This is normally the most time consuming activity when using CFD codes, (Hansen and Owen, 2008).

Instead of using body-fitted meshes like commercial CFDs (say CFX, Fluent, Star CCM+, etc), containment codes such as GOTHIC use a porous approach. With this approach, a porosity factor is applied to all cells and cell faces of the model affecting the cell volume and the cell face area. By blocking specific cells and cell faces, it is possible to represent the containment geometry (EPRI, 2016a). This approach allows to reduce the number of cells of the model relative to commercial CFD approaches, (Kim and Hong, 2015; Prabhudharwadkar et al., 2011).

Containment codes with a porous approach normally employ a Cartesian or cylindrical mesh, so it could be thought that the mesh generation is an unimportant and easy task. However, instead of repairing sliver surfaces as in commercial CFDs, in containment codes, this time-consuming task is replaced by the creation of a mesh that fits the implemented geometry maintaining fluid independence between different compartments. This last aspect may be affordable in simple geometries, but in complex configurations like a KraftWerk Union AG (KWU) containment building, it becomes a major shortcoming as the computational resources and time required become excessive.

Even though 3D containment models are gaining momentum, containment codes, such as GOTHIC or GASFLOW, have been historically not easy to use when dealing with the issues previously mentioned related with 3D models. Recently, GASFLOW-MPI development team has focused on issues such as parallelization (Xiao et al., 2017, 2016), or mesh creation and geometry implementation, (Yu et al., 2018). The geometry implementation time required in $3 \mathrm{D}$ modeling with this code has been reduced from weeks to minutes in line with the current simulation needs.

Regarding GOTHIC and similar porous CFD codes, this bottleneck is still an issue for its users that want to employ the 3D capabilities of the code. The mesh generation and geometry implementation normally require more than $40 \%$ of the time employed in a 3D containment analysis.

The need for efficiency in simulation and analysis of transients with GOTHIC containment 3D models have pushed the authors to develop a methodology for the creation and modeling of complex containments. In particular, the authors have created and applied this methodology to a GOTHIC containment model of Trillo NPP, a PWR-KWU located in Spain.

The present paper is organized into two different sections. The first one will depict the GOTHIC code, with special emphasis on its 3D modeling capabilities. In this section, the method used for constructing the KWU containment model will be depicted. The sec- ond section of the article will show a comparison between a fully 3D containment model and the equivalent LPM including a sensitivity analysis on modeling parameters. Finally, some conclusions will be drawn.

\section{Trillo NPP containment modeling with the GOTHIC code}

In this section, the GOTHIC code will be briefly depicted, highlighting its main benefits and drawbacks. After that, the LP and 3D modeling of containments and in particular Trillo NPP is presented.

\subsection{The GOTHIC code}

GOTHIC is an integrated, general-purpose thermal-hydraulics software package for design, licensing, safety and operating analysis of NPP containments, confinement buildings and system components. It solves the conservation equations for mass, momentum and energy for multi-component, multi-phase flow for three fields: gas mixture, continuous liquid and droplets. GOTHIC uses empirical 1D correlations for the heat transfer between the fluid and the heat structures rather than attempting to model the convection specifically. It also uses 1D correlation for the fluid friction with solid structures.

As commented, GOTHIC creates 3D geometries thanks to a porosity factor applied on each cell volume and face area in a pre-established Cartesian mesh. By blocking certain cells or cell faces, complex geometries can be modelled just modifying the porosity factor.

The 3D capabilities of GOTHIC in simulating basic flows for containment analysis have been extensively investigated, simulating Separate Effect Tests (SETs) in facilities like PANDA, CSTF, BFMC or CVTR, (EPRI, 2016b). A large validation effort against light gas experiments has been performed with $2 \mathrm{D}$ and $3 \mathrm{D}$ models, as can be seen in (Andreani et al., 2012, 2010; Hultgren et al., 2014; Paladino et al., 2010). Recent applications of GOTHIC 3D models involve research on hydrogen safety (Fernández-Cosials et al., 2017), steam discharges into a pool (Estévez-Albuja et al., 2018; Gallego-Marcos et al., 2018), filtered containment venting systems (Fernández-Cosials et al., 2018), depressurization transients in the High Temperature Gas Reactor (HTGR) (Yildiz et al., 2018), or the Fukushima accident analysis (Ozdemir et al., 2015). The code version used in the present study is GOTHIC 8.2 QA (EPRI, 2016b).

\subsection{Trillo NPP lumped parameters model}

As commented before, the LPM groups large regions into a single computational cell to perform the calculations. This implies that averaged quantities are used for the calculation. As only one or few cells have to be modeled, the time employed for modeling is relatively low, as well as its calculation time. Moreover, LPM creation process has straightforward established methodologies, see (Ofstun et al., 2013) or (Abdelghany et al., 2004). In this work, an LPM of Trillo NPP containment is developed to be compared against the 3D model. The LPM will be formed by a single Control Volume (CV), which will represent the full net volume of the Trillo NPP spherical containment on which the Thermal Conductors (TC) will be included.

Some of the most relevant parameters of a containment LPM are the net free volume and the thermal structures exposed area (shown in Table 1), which will influence the pressure and temperature during the transient. The results obtained with this LPM will be used for comparison in Section 3.2. 
Table 1

Main Variables of the LPM.

\begin{tabular}{|c|c|c|c|c|c|}
\hline Net Free Volume & Total TC Surface exposed & TC initial temperature & Liner thickness & Ambient Heat transfer coefficient & Ambient Temperature \\
\hline $61007 \mathrm{~m}^{3}$ & $19324 \mathrm{~m}^{2}$ & $45.3^{\circ} \mathrm{C}$ & $3.6 \mathrm{~cm}$ & $2 \mathrm{~W} / \mathrm{m}^{2} \mathrm{~K}$ & $25^{\circ} \mathrm{C}$ \\
\hline
\end{tabular}

\subsection{Three-dimensional GOTHIC containment modeling}

The process of creating a containment 3D model in GOTHIC or similar porous CFDs is not fully covered by any code manual neither guidelines, as it has been recently implemented. The method can be extremely time consuming because of the following reasons:

- The geometry implementation can be either a blind or an elongated process, as the GOTHIC graphical user interface refresh time to display the geometry take several minutes.

- GOTHIC can only implement certain type of geometries (wedges, caps, cylinders, blocks and torus), so the original geometry has to be simplified.

- The geometry and mesh implementation do not ensure hydraulic independence between unconnected containment compartments.

- To ensure hydraulic independence between compartments, trial and error tests have to be performed as the only option.
To overcome the first problem, the nuclear safety group at the UPM proposed a methodology that involves the creation of the geometrical model with CAD software (Bocanegra et al., 2016). This CAD software is used to include powerful visualization tools that allow the user to navigate through the geometry in an efficient and timesaving way. Additionally, it was suggested to build an intermediate CAD model of the containment, which was referred as simplified model, being formed solely by the geometries allowed in the correspondent code. For GOTHIC these geometries are wedges, cylinders, caps and torus, and the full containment is reconstructed with this method, see Fig. 1.

Then, thanks to a specifically developed script that extract the blockages coordinates of the simplified CAD model, the geometry implementation process has overcome many difficulties and increased its efficiency, reducing the time employed from a period of weeks to days.

KWU reactors were designed by the German company Kraftwerk Union $A G$, and this type of reactors have been mainly built in Europe. One of the particular features of this design is that the

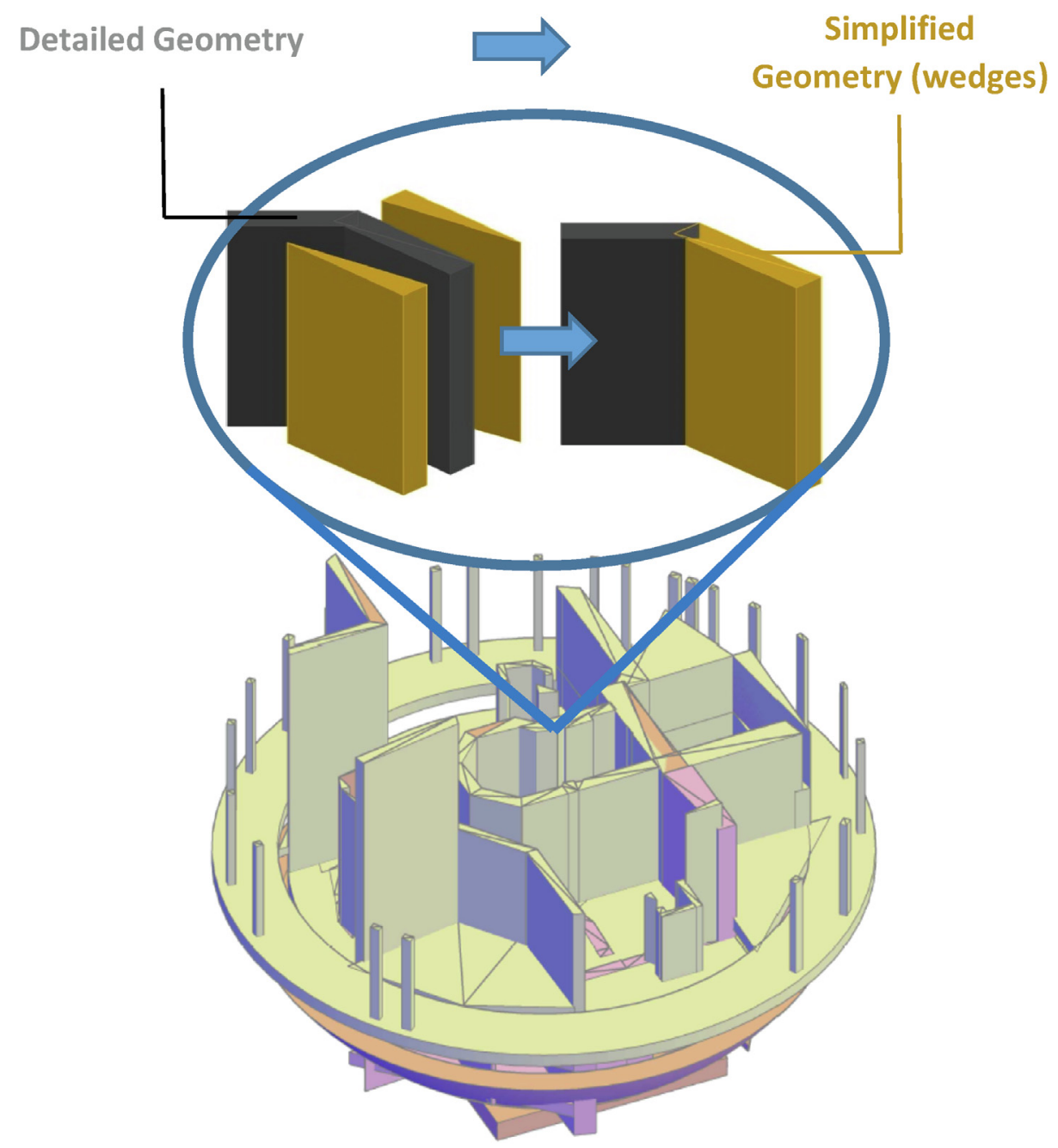

Fig. 1. Simplified Containment CAD Model visualization. 
containment liner shape is spherical instead of cylindrical allowing it to withstand a higher internal pressure. This internal sphere is made of steel and it is considered the main containment, so in an accident analysis, the containment is considered impaired if this liner fails. The sphere is covered by a concrete envelope; however, this structure is not designed to be leaktight. This design is similar to the large dry type with the exception of the spray system, which is normally inexistent in the PWR-KWU design. The typical free volume of a PWR-KWU containment is around $60000 \mathrm{~m}^{3}$.

The literature on KWU containment 3D models is somewhat scarce. The first study found, is the one previously mentioned from Royl et al. on which a SA is fully simulated, (Royl et al., 2000). Recently, the studies of Papini et al. (Papini et al., 2017, 2015) focused on the hydrogen behavior during a SA. A model with 40 CVs was employed to model the geometry, which includes several 3D connectors and Flow Paths (FLs) that may induce some instabilities in the simulation, increase the CPU computational effort and have some downsides representing 3D flows. This is due to the fact that flow paths only transport variables through advection, and not through diffusion. The study of Lopez-Alonso et al., uses the same model, with the same problematic, (Lopez-Alonso et al., 2017).

The study of (Bocanegra et al., 2016) applied its methodology in a PWR-W large dry containment. This was possible as this type of containment is less compartmentalized, and the hydraulic independence between compartments can be achieved with a reasonable cell size. As mentioned before, if the gridline separates fluid between regions, the interconnecting cell faces must be completely blocked. In this sense, in a PWR-KWU containment, the cell size required to assure fluid separation, using a single $\mathrm{CV}$ to avoid the use of FLs, is impracticable because of the large number of thin and non-orthogonal walls. In this case, cell sizes smaller than $0.4 \mathrm{~m}$ length would be needed, which would make the 3D model compounded of more than a million cells, which is totally unaf- fordable for porous CFD codes like GOTHIC 8.2 (QA), which has a limitation on $100 \mathrm{k}$ cells.

To surmount this obstacle, a novel procedure is proposed for complex containment modeling. In this procedure, instead of the simplified model, another intermediate model is created, referred as the Geometrically Simplified Grid Adapted (GSGA) model. This approach marches the commercial CFDs reverse path of the meshing procedure. Instead of starting with a geometry, and then create a computational mesh that fits such geometry, in the GSGA model, a mesh will be first created and then, the geometry will be rebuilt around it to assure the containment compartments fluid independence.

The steps of this procedure are the following:

1. Creation of the detailed CAD model. This part is equal to the one proposed in (Bocanegra et al., 2016). The plant layouts are used, and the reconstruction should be as detailed as possible (Fig. 2), as this model will be used not only for the creation of the simplified model, but also for thermal conductor data extraction and visualization purposes in the results post-processing.

2. Creation of the mesh in the CAD environment. Within this procedure, there are no restrictions for the mesh creation in terms of hydraulic independence between compartments as shown in Fig. 3. The selected mesh can be homogeneous in $\mathrm{X}, \mathrm{Y}$ and $\mathrm{Z}$ directions, or not, in order to reduce the number of cells in a certain direction. The mesh has to be coarse enough to be able to work and simulate a specific transient with a reasonable computational cost. The mesh used in this study has a cell size based on similar and previous works, (Fernández-Cosials et al., 2017; Jimenez et al., 2017; Papini et al., 2017, 2015). The total number of cells is 44800 but the number of active cells (not-fully blocked) is 21300 .

3. Reconstruction of the containment geometry based on the mesh. In this step, the complete geometry of the detailed CAD is reconstructed in order to assure hydraulic independence as shown in

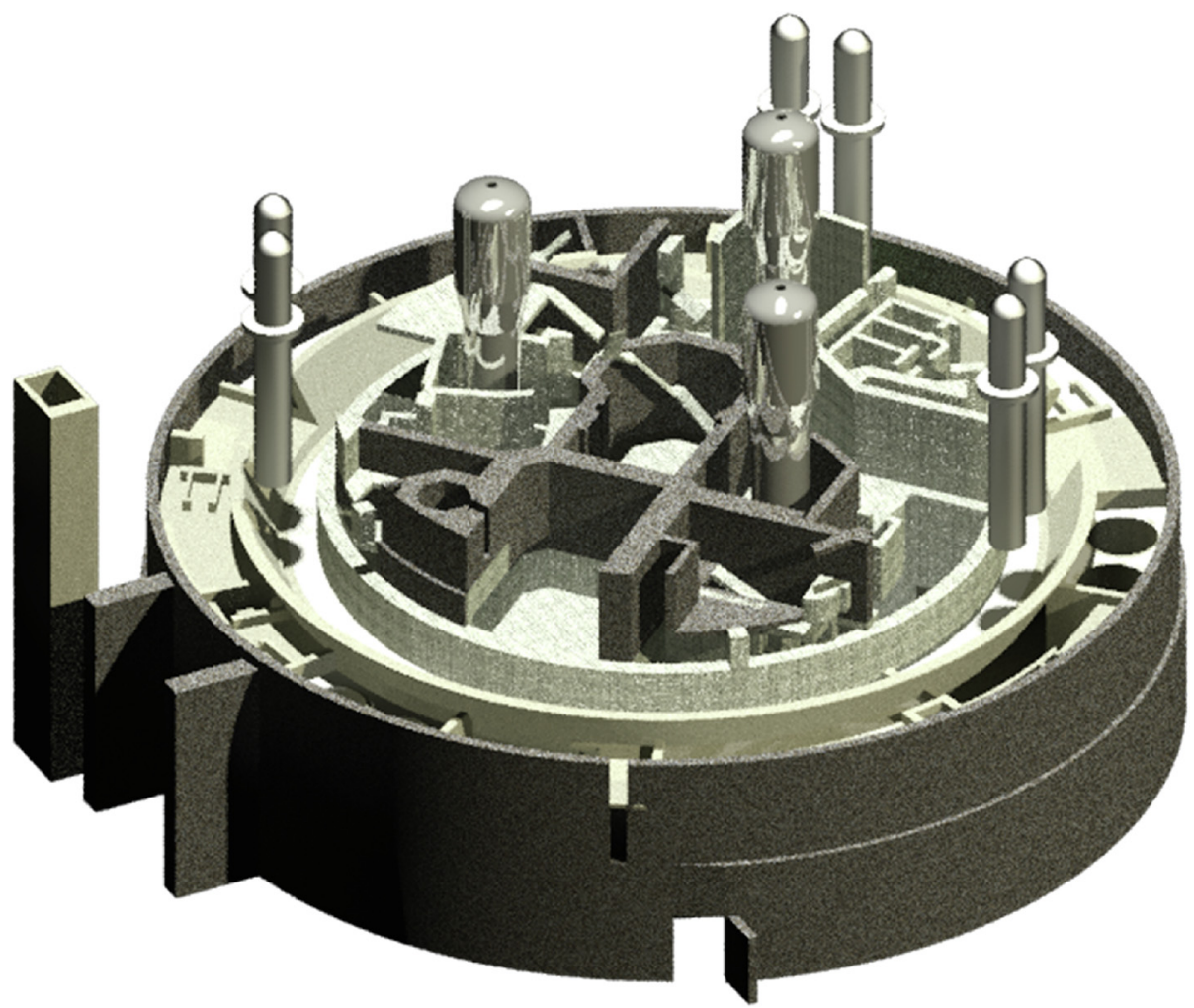

Fig. 2. Detailed Trillo NPP CAD model visualization. 


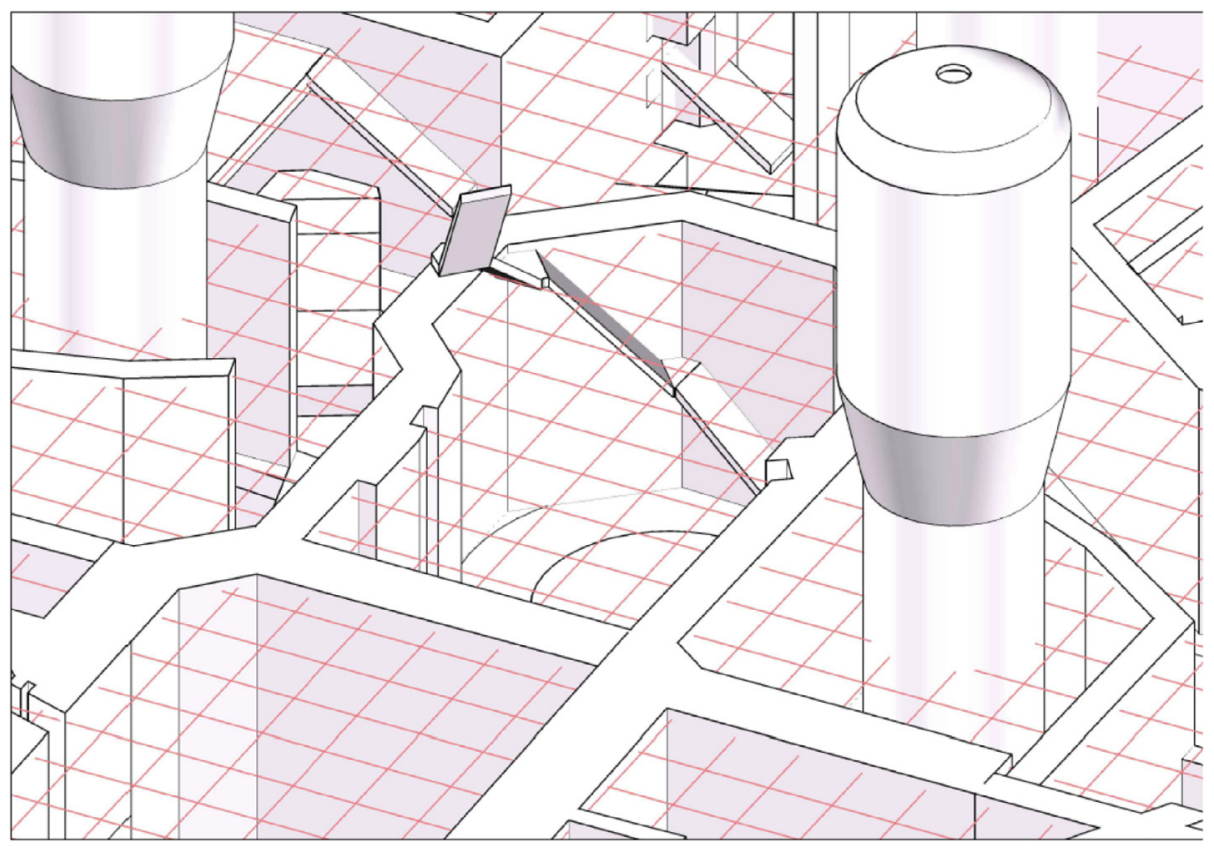

Fig. 3. Detailed CAD model, imbibed with the mesh.

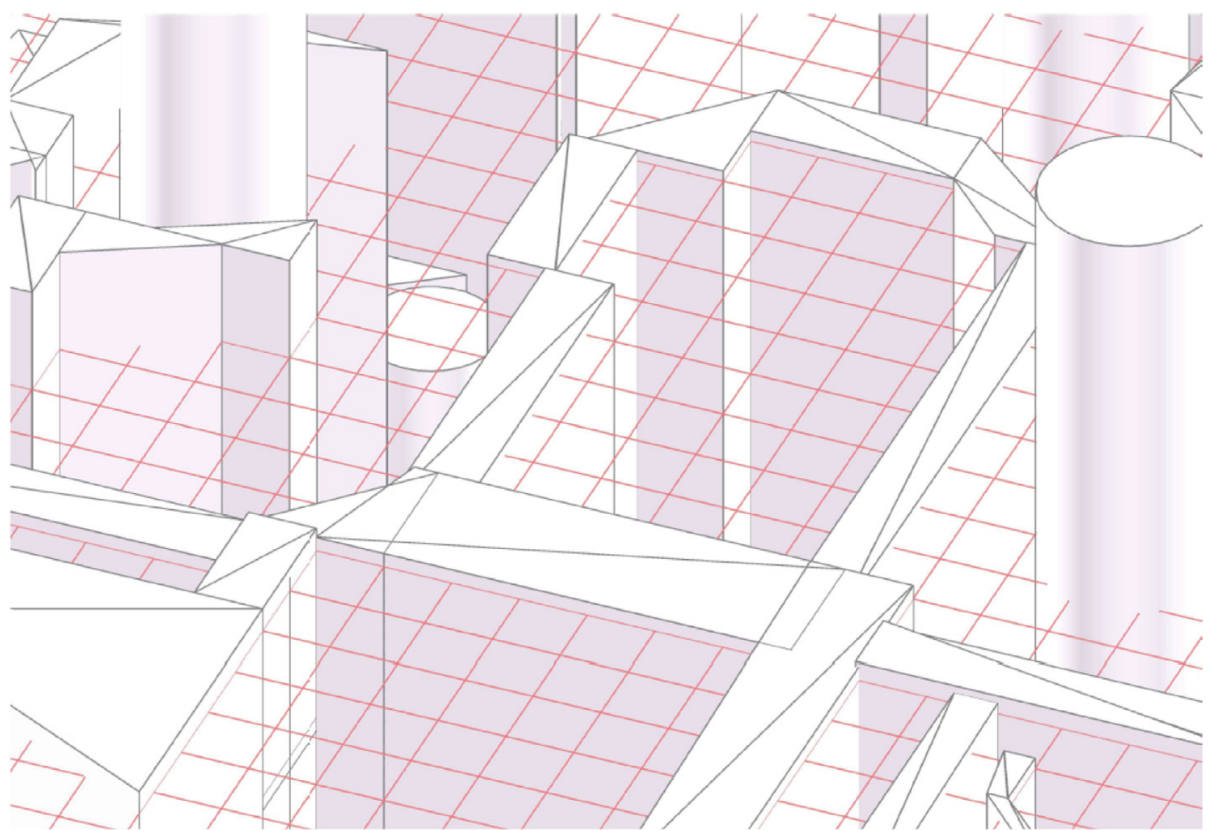

Fig. 4. GSGA CAD model imbibed with the mesh.

Fig. 4. All the walls can be sharply modified to achieve this goal. Thanks to the visualization of a CAD software, it is easier to perform this geometry modification. The process is divided into two steps: first, all components of the geometry are modelled as wedges; this is because wedges can be adapted to almost any shape by its combination, see Fig. 1 . The walls that have to be hydraulically independent are localized by the user. Then the cylindrical components (vessel, pressurizer, steam generators etc.) are added as well as the spherical liner.

In comparison, instead of the simplified CAD model developed by (Bocanegra et al., 2016), the GSGA model is obtained. The net free volume varies during this process because of the geometry adaptation to the grid. Its influence on the results will be discussed later in Section 3.3.

4. Implementation of the CAD geometry into the GOTHIC code. Once the GSGA model is obtained, the next step is to extract all necessary data from the CAD model and implement it into GOTHIC. This is normally done with specific scripts.

5. Implementation of the TC in the GOTHIC code. To insert the TCs in the GOTHIC code a similar approach is used. All TCs are modeled in the CAD model, so they can be easily extracted and inserted into the GOTHIC code. As shown in Fig. 5, this step by step process allows the user to gather all relevant information in the CAD file, making its access and identification an easy and time-saving task. 

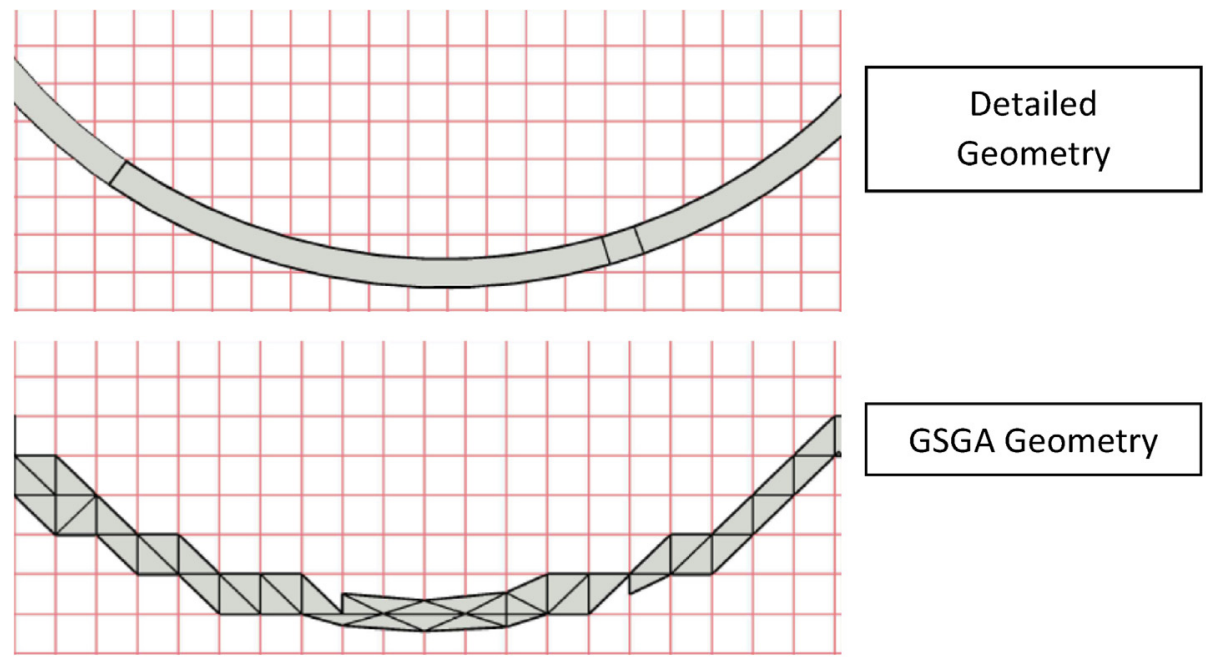

\section{GSGA Geometry}

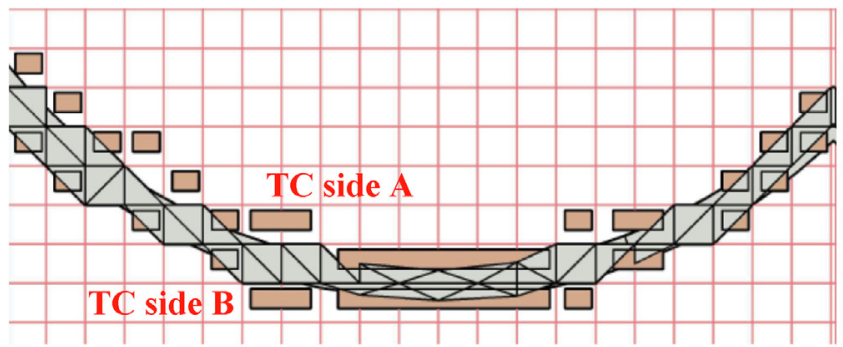

\section{GSGA Geometry \\ with TCS}

Fig. 5. Circular walls approach with GSGA and Thermal Conductors.

This way of implementing the TCs is a step forward in the previous work of (Bocanegra et al., 2016).

The presented method for containment modeling in a single $C V$, especially for complex ones such as a PWR-KWU, allows the user to reduce the time spent in geometry and TC implementation, as well as in model modification and verification. Additionally, it ensures that the mesh used will treat correctly the different fluid regions, which is one of the main challenges of porous CFD codes that use Cartesian or polar meshes.

With the current methodology and scripting, the time used to create and operate the model is highly reduced. The time reduction is not as extensive as the time obtained with the method of $\mathrm{Yu}$ et al. for GASFLOW-MPI code, (Yu et al., 2018). However, this last method still lacks of assuring hydraulic independence between different containment compartments if the mesh is not carefully chosen.

The characteristics of the GSGA model are the same as for the LPM shown in Table 1. All parameters that could be kept the same as the LPM are maintained in the GSGA model, in order to minimize the differences caused by the change in the modeling strategy. A section of the GSGA GOTHIC model front and top view can be seen in Fig. 6 .

Once the geometry is implemented in GOTHIC, other parameters have to be selected for a GSGA GOTHIC model, see Table 2. In this case, the pressure matrix solution method used was conjugate with the flux variables calculated up-stream with a space
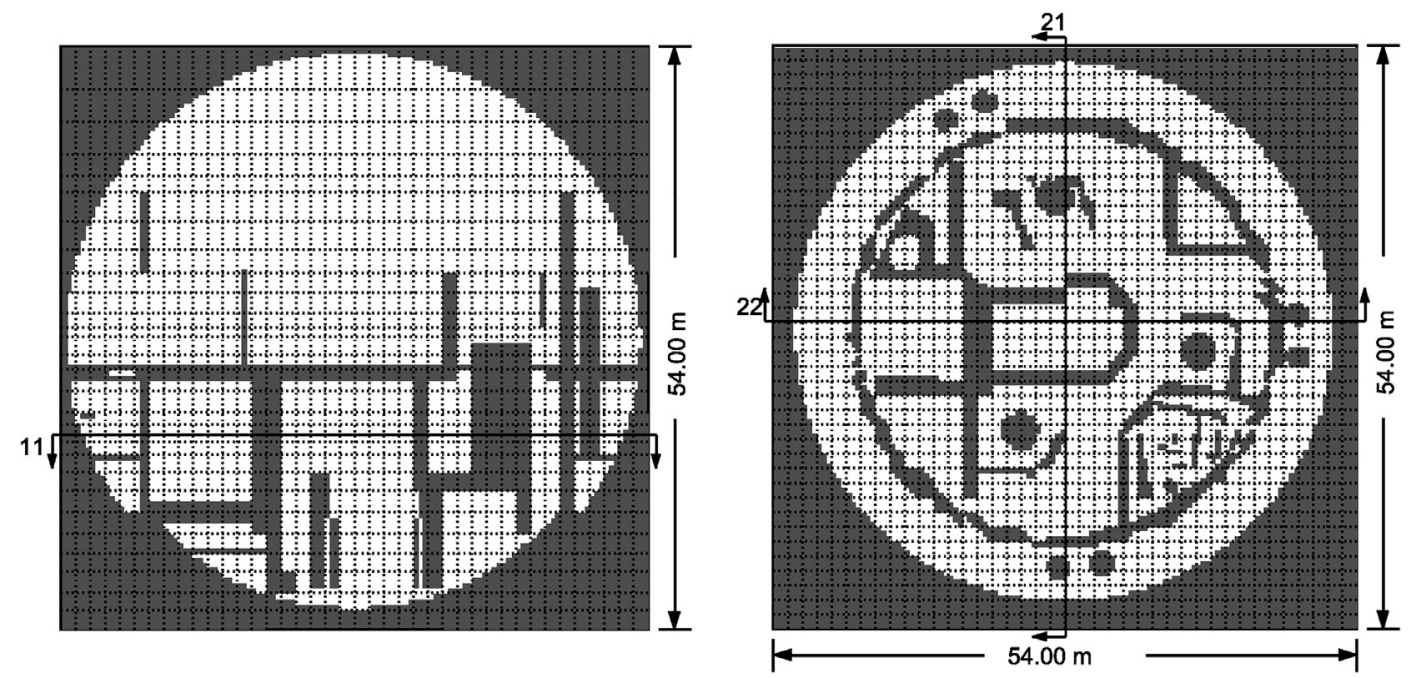

Fig. 6. GOTHIC GSGA model of Trillo NPP containment. 
Table 2

Trillo GSGA containment model parameters.

\begin{tabular}{|c|c|c|c|c|c|c|}
\hline Turbulence Model & Molecular Diffusion & Minimum Porosity & Pressure Control & Enthalpy Control & Max Time step & Discretization scheme \\
\hline k- $\varepsilon$ standard & Enabled & 0.03 & $6 \mathrm{kPa}$ & $4 \mathrm{~kJ} / \mathrm{kg}$ & 0.01 & FLSOUP \\
\hline
\end{tabular}

differencing scheme of second order with flux limiter (FLSOUP). The control for the pressure and enthalpy variation from one iteration to another was set to $6 \mathrm{kPa}$ and $4 \mathrm{~kJ} / \mathrm{kg}$. If the change in these controls exceeds a limit, the time step is reduced. Additionally to the previous parameters, the CFL condition is controlled with the time step. The minimum porosity is defined as the minimum cell volume or cell face porosity that will be allowed in the model and it is set to 0.03 . If the calculated porosity is less than minimum porosity, then the cell or cell face will be completely blocked with a porosity value of zero.

\section{Results and discussion}

To evaluate the solution provided by the GSGA model, a comparison of the results between the LPM and the GSGA during a LBLOCA is performed. The target variables will be the pressure and temperature peak, as well as the relaxation in pressure and temperature caused by condensation in the thermal structures.

The M\&E release input data is obtained from a MELCOR model of a 3 loop PWR-W of 1000 MWe. This model has been previously used in studies such as (Ruiz-Zapatero et al., 2016), with reasonable results. The selected transient is a LBLOCA with the break located in the cold leg of loop 1 . The equivalent size of the break is $0.7 \mathrm{~m}$ (cold leg diameter), but it is not modelled as a doubleended guillotine break. The Safety Injection System (SIS) is considered available during the accident. The M\&E release input data can be seen in Fig. 7. The flow is injected as droplets of $0.01 \mathrm{~cm}$ as suggested in (Dominion, 2006). This academic M\&E release input is used only to illustrate the capabilities of the 3D model and no real values of the plant can be expected.

\subsection{Lumped parameters model results}

The results of the transient are shown in Fig. 8. The pressure peak occurs at $8 \mathrm{~s}$, reaching a value of $156 \mathrm{kPa}$. At $100 \mathrm{~s}$, the pressure has been reduced to $137 \mathrm{kPa}$, showing that the internal structures and the external atmosphere are able to partially remove the heat produced. The temperature peak occurs at the same time as the pressure peak and starts to decrease afterwards because of the heat transfer with the TCs. The calculation time was around 45 s using a single CPU with $3.2 \mathrm{GHz}$.

\subsection{GSGA GOTHIC model results}

The results are shown in Figs. 9-12. It is seen that the pressure peak (Fig. 10) occurs at $8 \mathrm{~s}$, reaching $153 \mathrm{kPa}$ almost homogeneously. An early pressurization appears in the rooms close to the break. The pressure then decreases as a result of the steam condensation that occurs over the containment structures. The comparison between the 3D model average pressure and the LPM shows that the behavior is equal, with small differences in value. The pressure reached by the LPM tends to be higher, because the

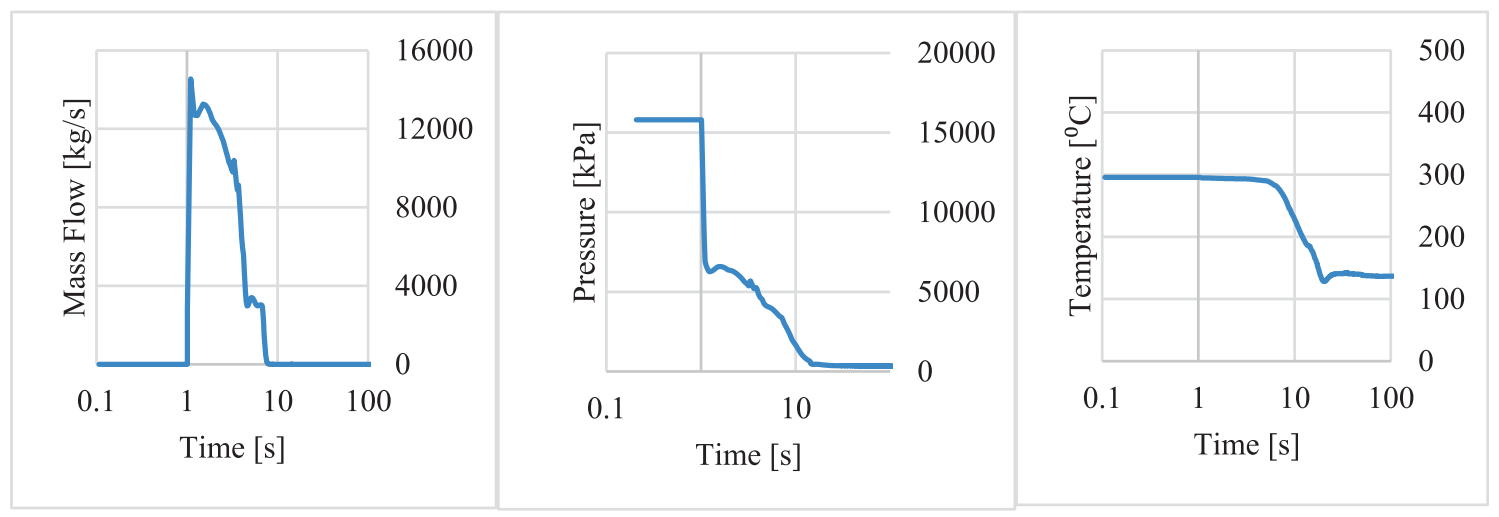

Fig. 7. Mass flow (a), Pressure and Temperature (b) of the M\&E Release.

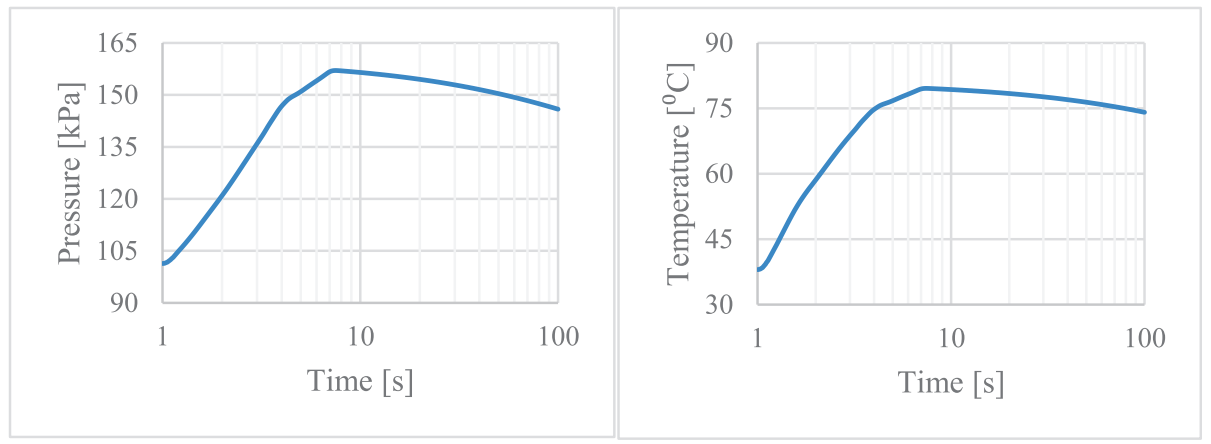

Fig. 8. Pressure and Temperature of the Lumped model. 


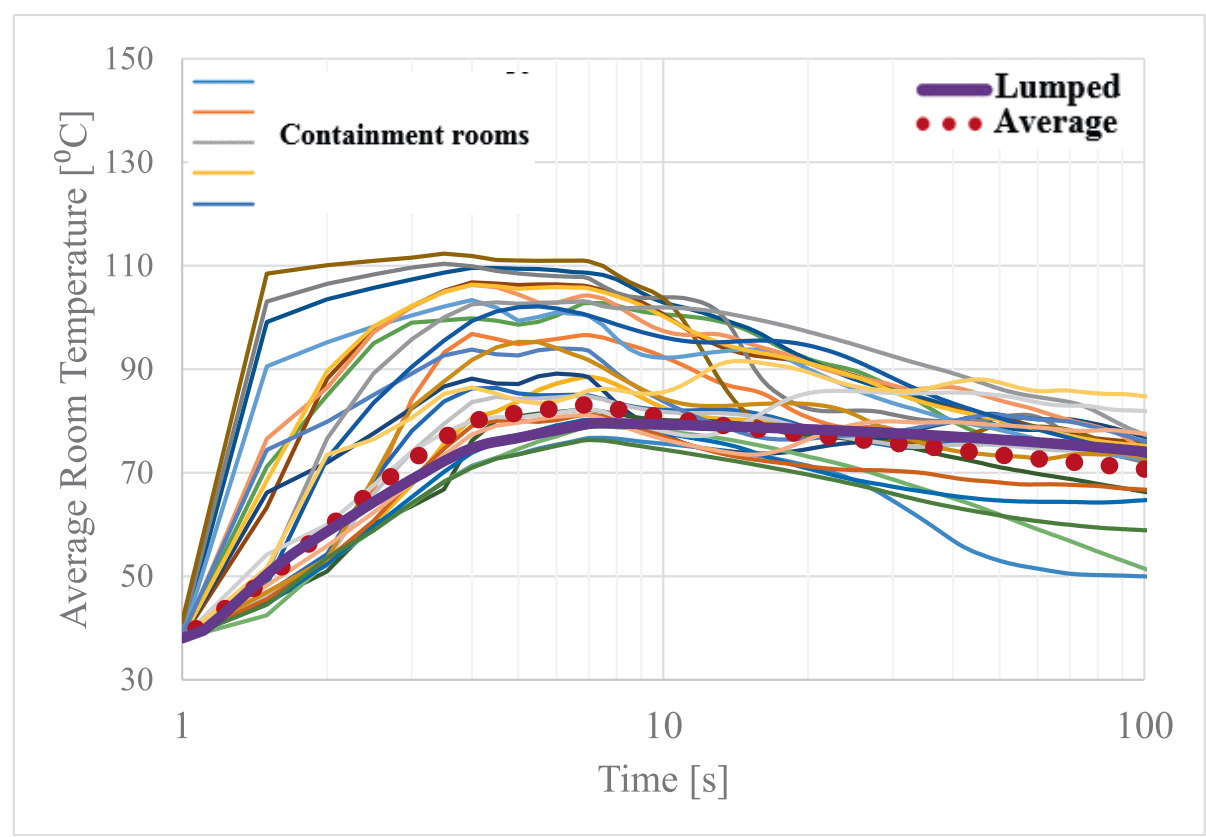

Fig. 9. Average Room temperature evolution, including the LPM and the full GSGA average.

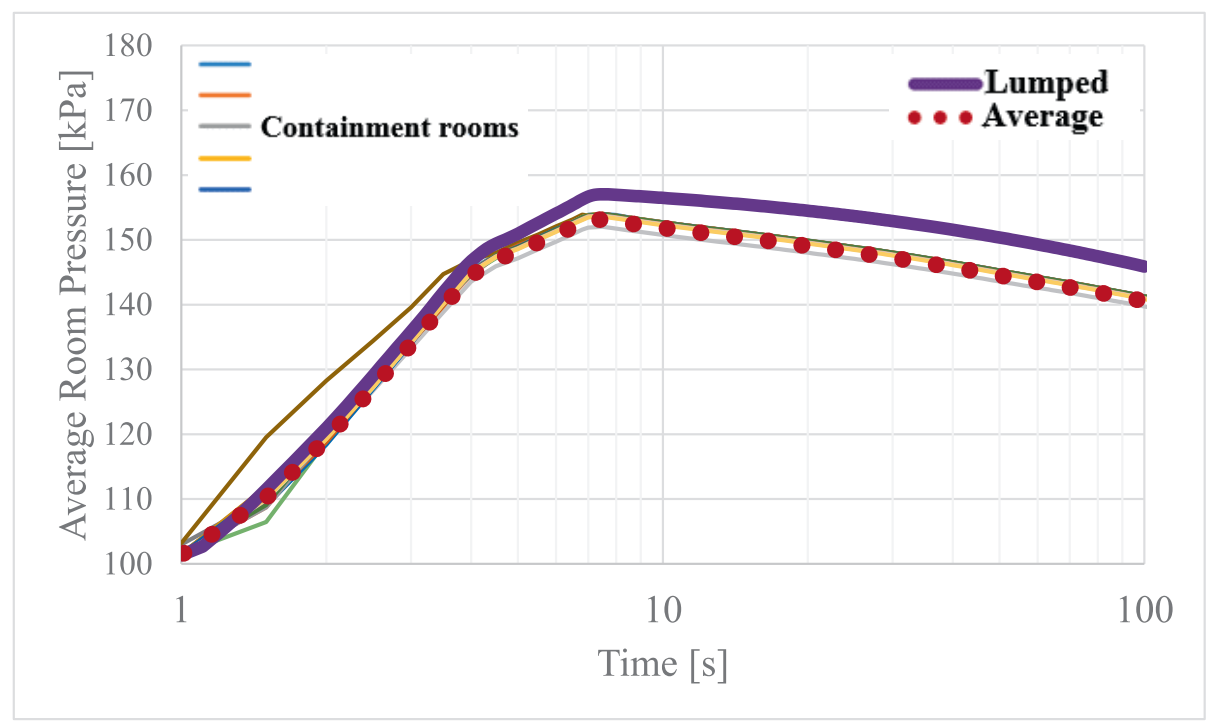

Fig. 10. Average Room pressure evolution, including the LPM and the full GSGA average.

condensation rate is lower when this approach is used. This is because, contrary to the GSGA, the Non-Condensable Gases (NCGs) cannot be displaced by the steam and therefore, the NCGs fraction becomes different in the TCs surroundings of the GSGA relative to the LPM. The GOTHIC condensation model used takes into account the NCGs as they affect negatively to the steam condensation, (de la Rosa et al., 2009).

Fig. 9 shows a heterogeneous temperature evolution. As noted in previous analyses, the average temperature of the LPM and the 3D model are similar in behavior and value, (Jimenez et al., 2017). However, as the temperature is transported slower than pressure, it does not reach homogeneity at any point during the simulated transient.

Relative to LPM results, a 3D model provides extra data. For example, streamlines formed by the steam path allow to observe characteristic patterns, see Fig. 11 . The 3D streamlines can be the desired parameter to study regarding light gas distribution during a SA. Additionally, the maximum temperatures of each room can be extracted, as shown in Fig. 12. The extracted maximum temperatures present a higher dispersion of values than the average values. As pointed out in recent studies, these temperatures can be used to limit the equipment environmental qualification as they are more accurate than the average temperatures provided by a LPM (Jimenez et al., 2017). For a KWU containment, this approach can be of utmost importance because of its highly compartmentalized geometry.

The computational time needed to run a short-term LBLOCA with the GSGA model is extended compared to the LPM, (10 h compared to $45 \mathrm{~s}$ ) using restrictive time steps and a single core of $3.2 \mathrm{GHz}$. The parallelization capability of GOTHIC decreases this time as several CPUs can be used. Comparing the pressure and temperature results, the LPM provides accurate results in very 
Time: 1.5 seconds

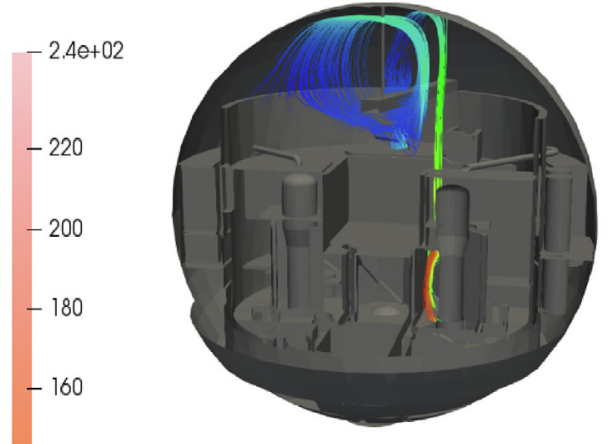

Time: 4.5 seconds

$-100$

$-80$

$-60$

$-40$

$-20$

$-0.0 e+00$

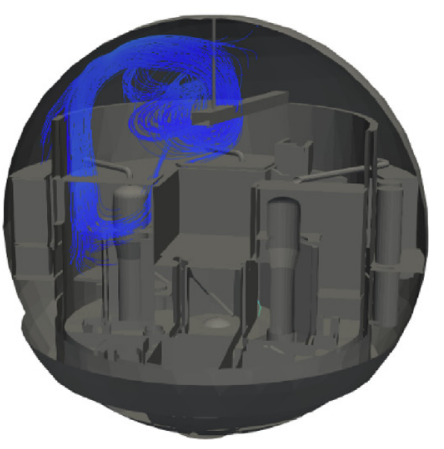

$\frac{0}{5}$
$\frac{5}{3}$
$\frac{7}{0}$
$\frac{0}{10}$
$>$

Time: 2.5 seconds

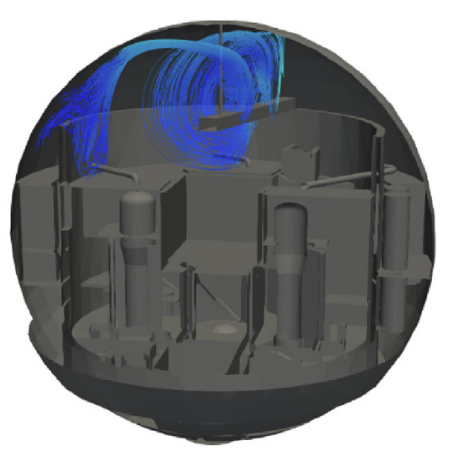

Fig. 11. Streamlines in Trillo GSGA GOTHIC model during the transient.

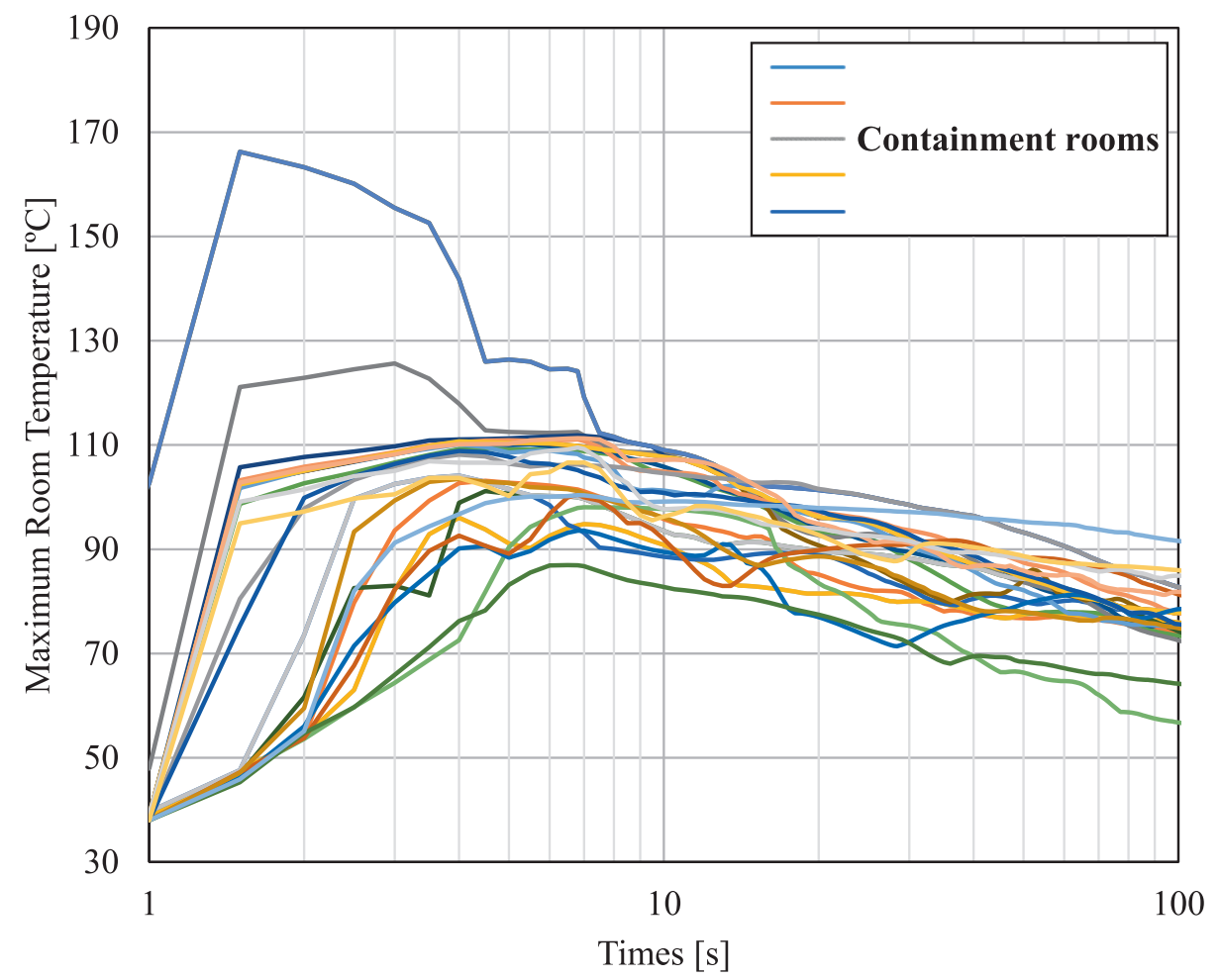

Fig. 12. Maximum temperatures evolution in all Rooms of Trillo GSGA GOTHIC model. 
Table 3

Sensitivity analysis values for TC exposed area and net free volume.

\begin{tabular}{|c|c|c|c|c|c|c|c|c|c|}
\hline & Base Case & Case 1 & Case 2 & Case 3 & Case 4 & Case 5 & Case 6 & Case 7 & Case 8 \\
\hline TC Exposed Area & $19384 \mathrm{~m}^{2}$ & $19869 \mathrm{~m}^{2}$ & $20353 \mathrm{~m}^{2}$ & $18899 \mathrm{~m}^{2}$ & $18415 \mathrm{~m}^{2}$ & $19384 \mathrm{~m}^{2}$ & $19384 \mathrm{~m}^{2}$ & $19384 \mathrm{~m}^{2}$ & $19384 \mathrm{~m}^{2}$ \\
\hline Net Free Volume & $61007 \mathrm{~m}^{3}$ & $61007 \mathrm{~m}^{3}$ & $61007 \mathrm{~m}^{3}$ & $61007 \mathrm{~m}^{3}$ & $61007 \mathrm{~m}^{3}$ & $62532 \mathrm{~m}^{3}$ & $64057 \mathrm{~m}^{3}$ & $59482 \mathrm{~m}^{3}$ & $57957 \mathrm{~m}^{3}$ \\
\hline
\end{tabular}

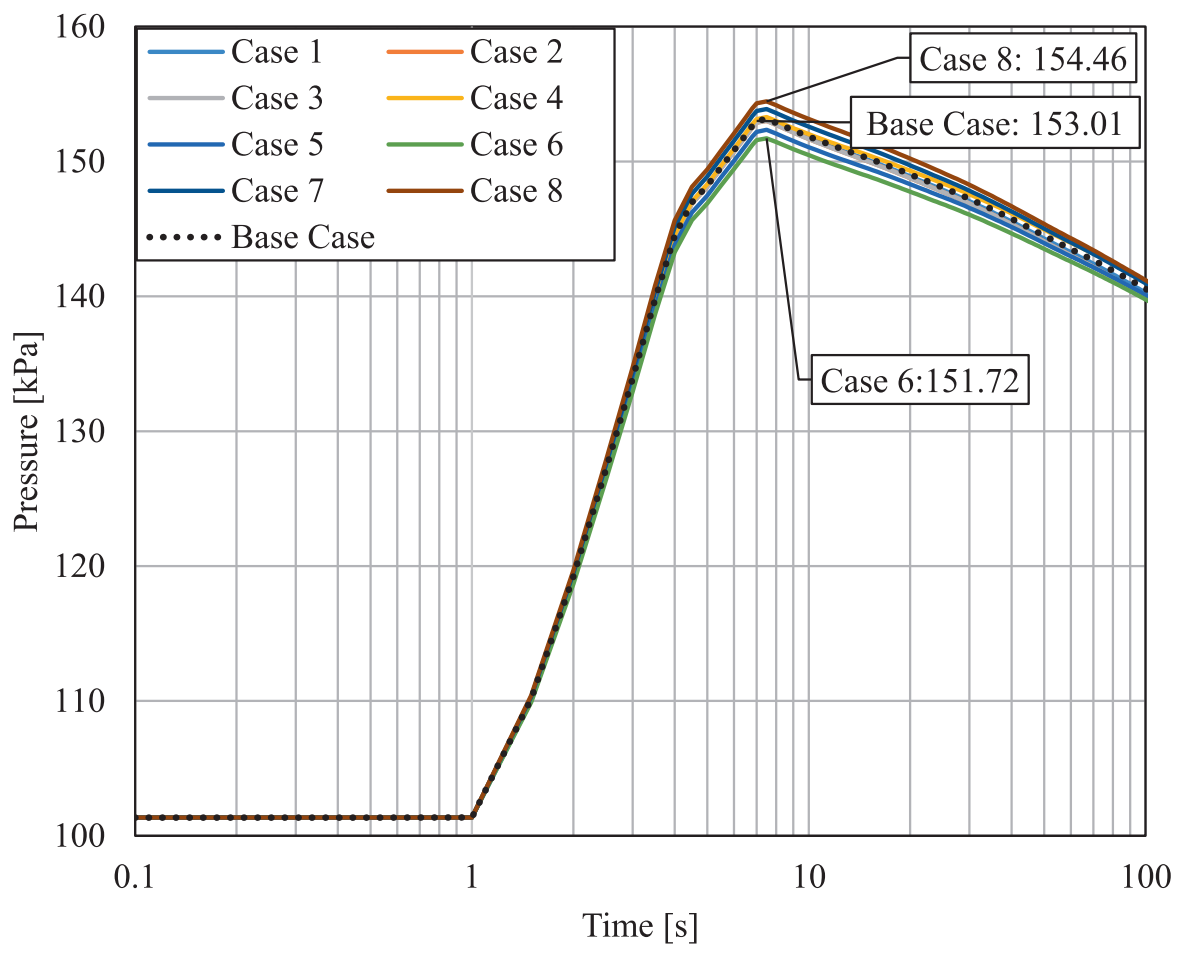

Fig. 13. Average pressure of the sensitivity analysis cases during the transient.

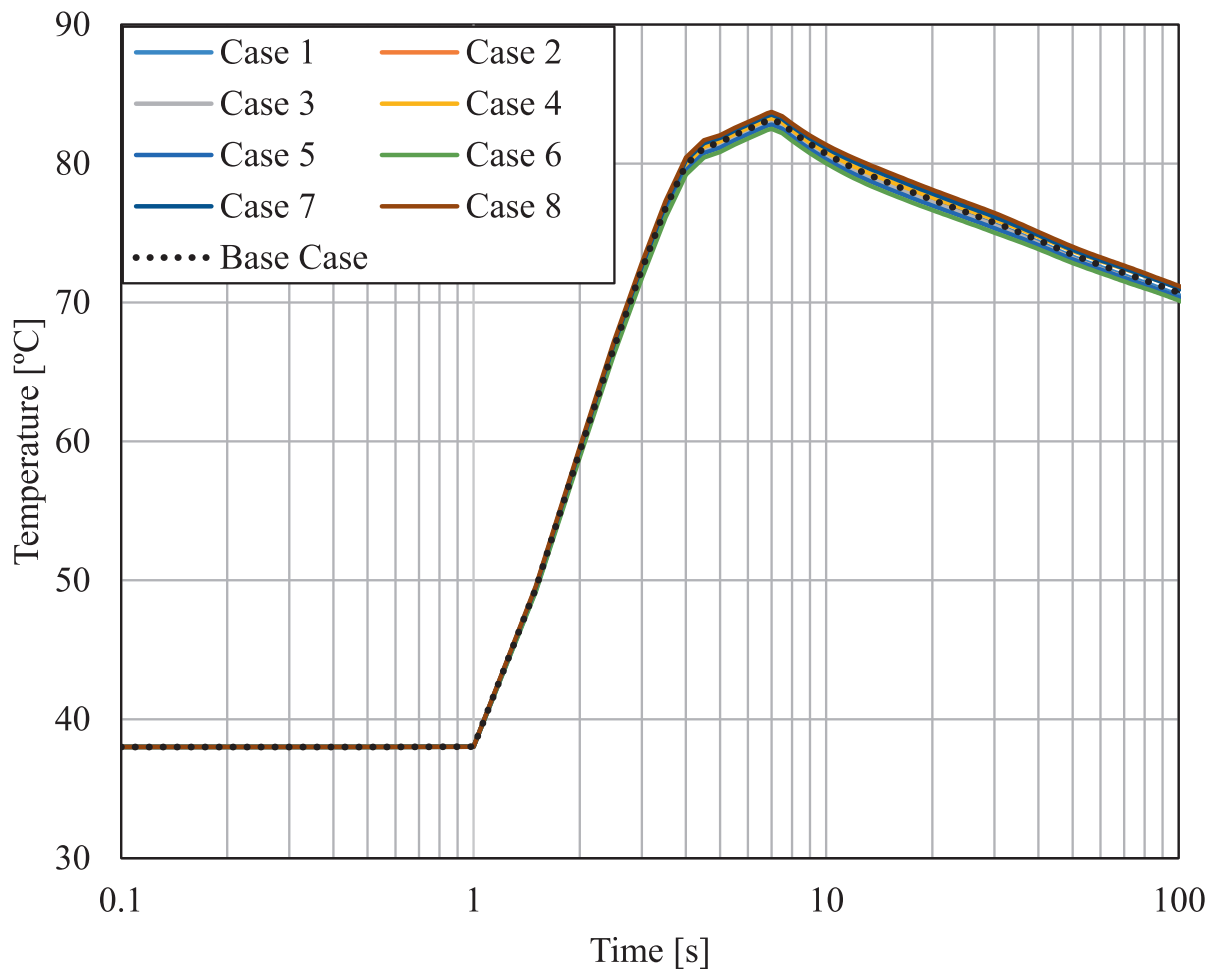

Fig. 14. Average temperature of the sensitivity analysis cases during the transient. 
short periods of time, which makes it adequate for preliminary or averaged results analysis.

\subsection{Sensitivity study}

Even though the GSGA model needs higher computational resources than the LPM, those are considerably smaller than the required by a commercial CFD such as Fluent or CFX. This facilitates the development and analysis of a sensitivity study. The previously discussed GSGA model will be labeled as Base Case, and the sensitivity cases are shown in Table 3. The Base Case is used to cal- culate the relative differences in average pressure and temperature.

The sensitivity is made on two modeling variables, the net volume, and the heat structures surface area exposed. These variables represent two of the main uncertainty and inaccuracy contributors in a containment model developed from CAD (Wang and Yang, 2017) and specifically with a GSGA model. The layouts detail does not normally allow a high accuracy calculation of its values, and errors can be committed. A variation of up to $5 \%$ is used because it falls under the range of reasonable deviation. The variation in TC exposed area is made increasing or decreasing it in all TC. The

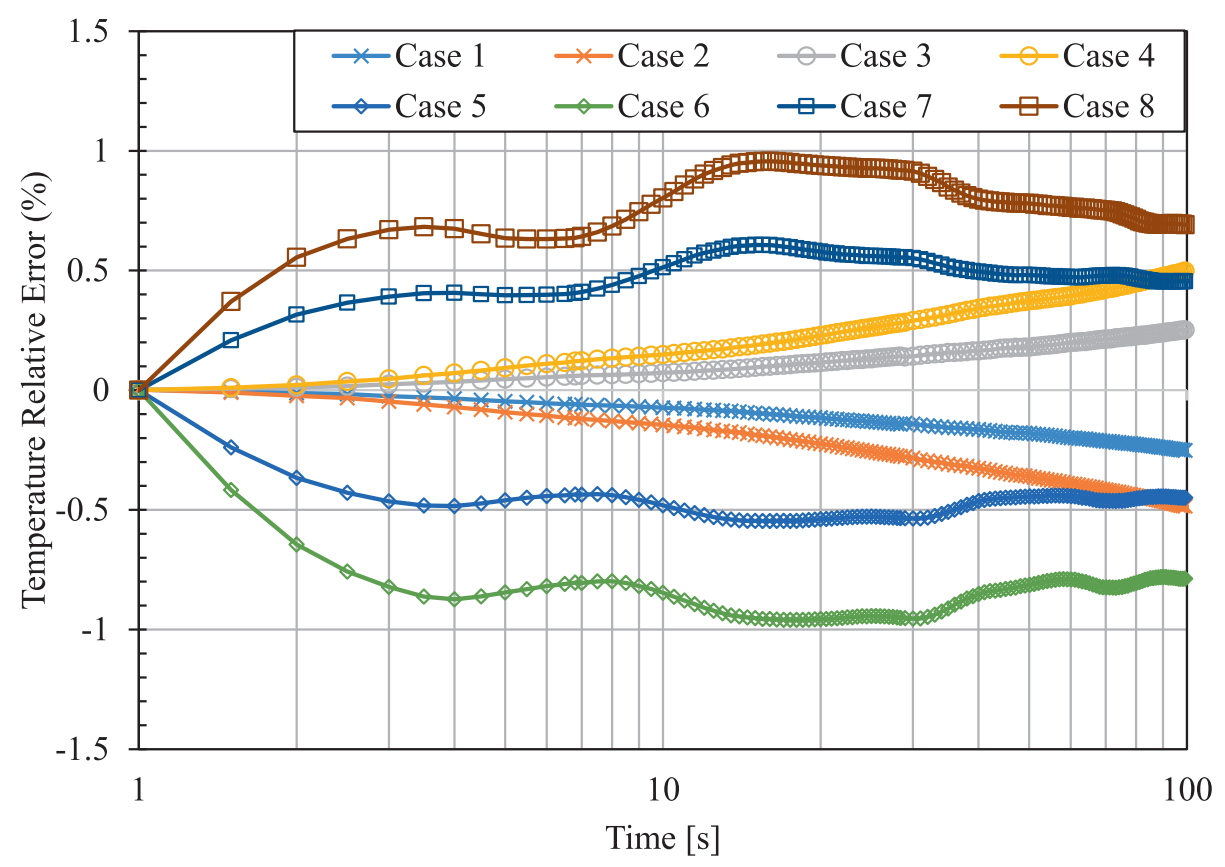

Fig. 15. Relative difference in temperature of the sensitivity analysis cases and the base case.

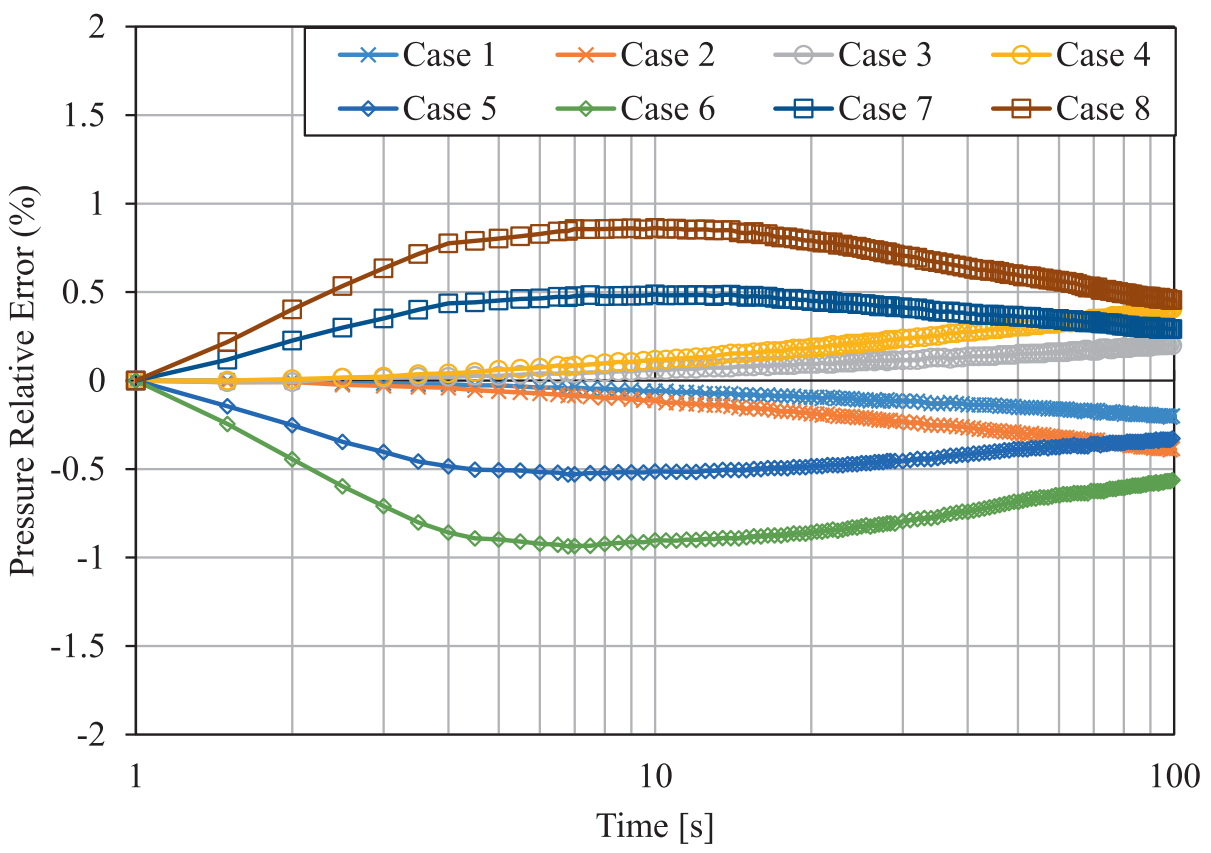

Fig. 16. Relative difference in pressure of the sensitivity analysis cases and the base case. 
variation in net volume is made adjusting the radius of the spherical liner.

The sensitivity analysis results are shown in Figs. 13-16. The pressure rises similarly among all simulations. The differences appear when the pressure reaches the peak, when the maximum differences are close to $1 \%$ for Cases 8 and 6, on which there is a $5 \%$ variance in net volume. It is remarkable that the differences found during the pressure peak in Case 6 and 8, are almost equal each other, (0.86\% and $0.93 \%)$, which supports the robustness of the model and prediction capability. The influence of the TC area exposed during the pressure peak is limited compared to the net volume. The differences are less than $0.1 \%$ during the pressure peak as $\mathrm{TC}$ have not interacted with the $\mathrm{M} \& \mathrm{E}$ release enough.

As the transient develops, the differences caused by the net volume start to decrease. The decrease in the pressure difference for Cases $5-8$ is caused because the pressure in a sensitivity with lower net volume reaches a higher pressure during the blowdown, see Fig. 13; this enhances condensation, decreasing the pressure, while the contrary decreases the condensation rate.

The discrepancies between Cases 1-4 and the Base Case continue growing during the full transient, even though they are relatively small at the end of the simulation (under $0.5 \%$ ). In a longer transient, the differences caused by a different TC exposed area have an uprising tendency, given that the condensation becomes the dominant phenomenon that influences the properties of the containment during that time.

Regarding the average temperature in the containment, its evolution is similar among all cases, see Fig. 14. The average temperature peak appears at the same time and the following descent is also alike. The relative differences during the temperature peak are slightly lower than the pressure discrepancies; less than $0.85 \%$ at the maximum of all cases. The evolution of relative differences in temperature after the peak is similar to that in the pressure. The influence of the TC surface area becomes inappreciable during the peak, but it starts increasing during the transient until reaching $0.5 \%$ at $100 \mathrm{~s}$. The relative differences of Cases $5-8$ do not have a monotonic behavior, and they seem to stabilize after $10 \mathrm{~s}$. The differences reached at $100 \mathrm{~s}$ are higher than the differences in pressure.

\section{Conclusions}

The modeling of an NPP containment has been historically a challenging task. Initially, they were modeled with a LP approach, and only recently 3D models are starting to be used. However, the time and resources consumed in the development of a 3D containment model have been unaffordable for most of the users. Thus, despite the benefits and details acquired when using 3D containment models, this fact has delayed the introduction of this approach into regular applications.

Thus, Based on the previous steps proposed in (Bocanegra et al., 2016), a methodology to create a 3D containment model of a heavy compartmented containment with the GOTHIC code with an affordable cost is proposed. The model created in this study is based on Trillo NPP. Similarly to (Bocanegra et al., 2016), the methodology proposed involves the use of CAD software as a main support during the modeling process.

This methodology involves the creation of a Geometrically Simplified Grid Adapted (GSGA) model, which encompasses the model creation based on a pre-existing mesh and only including the geometry allowed by GOTHIC. It permits the containment modeling in a single $\mathrm{CV}$, which increases the accuracy of the simulation, allows 3D streamlines studies and avoids the use of flow-paths. Additionally, TCs are first modeled in the CAD environment and later included in GOTHIC via a specific script to reduce the time the user employs in implementing them. The time employed to create the model has considerably reduced thanks to several tools which help to transfer the CAD data to the GOTHIC containment model.

As a case study, a LBLOCA is simulated in the containment 3D model. The comparison of the 3D model results with a LPM reinforces the conclusions extracted in the previous works, on which it is stated that the average pressure and temperature of a LPM and the 3D model are similar. The LPM pressure is slightly higher because of the NCGs and the condensation model used. The average temperature is similar in both cases as well, however, the average temperature of the LP approach does not actually represent any behavior, nor in the dome or liner, neither in any containment compartments.

Additionally, a sensitivity study of the 3D model has been presented varying two of the main parameters that normally hold inaccuracy: the containment net volume and the TC area. The sensitivity study shows that small variations of these two parameters in a range of $5 \%$ do not strongly influence the results during the pressure peak and in the short term. A priori, errors generated by using this method does not significantly influence the results.

With the current methodology employed, the modeling of a containment building with a complex geometry such as a KWU, an ESBWR or an EPR with the GOTHIC code can be done in a time-saving manner. By making this task easier, the use of 3D models, along with the benefits obtained for its use, is enhanced.

As future works, the multi-zone approach with mesh refinement will be tested; in addition to simulating a double-ended guillotine break with BE settings of the M\&E release.

\section{Acknowledgments}

The authors acknowledge Centrales Nucleares Almaraz-Trillo for its valuable support, trust and help during the development of the 3D models.

The authors acknowledge the computer resources and technical assistance provided by the Centro de Supercomputación y Visualización de Madrid (CeSViMa).

The authors want to express their deep gratitude to EPRI and Zachry company personnel, especially Tom George and Jeff Lane, for their valuable technical support and help.

\section{Appendix A. Supplementary data}

Supplementary data to this article can be found online at https://doi.org/10.1016/j.anucene.2019.05.041.

\section{References}

Abdelghany, J.M., Guimond, P.J., Higar, K.E., Wissinger, G.J., Framatome ANP, I., 2004 Analysis of Containment Response to Postulated Pipe Ruptures Using GOTHIC, BAW-10252(NP) Revision 0.

Andreani, M., Kapulla, R., Zboray, R., 2012. Gas stratification break-up by a vertical jet: simulations using the GOTHIC code. Nucl. Eng. Des., 71-81 https://doi.org/ 10.1016/j.nucengdes.2011.06.004.

Andreani, M., Paladino, D. George, T., 2010. Simulation of basic gas mixing tests with condensation in the PANDA facility using the GOTHIC code. Nucl. Eng. Des. 240, 1528-1547. https://doi.org/10.1016/j.nucengdes.2010.02.021.

Bocanegra, R., Jimenez, G., Fernández-Cosials, M.K., 2016. Development of a PWR-W GOTHIC 3D model for containment accident analysis. Ann. Nucl. Energy 87, 547-560. https://doi.org/10.1016/j.anucene.2015.10.022.

Chen, Y., Wu, Y.W., Wang, M.J., Zhang, Y.P., Tan, B., Zhang, D.L., Tian, W.X., Qiu, S.Z., Su, G.H., 2018. Development of a multi-compartment containment code for advanced PWR plant. Nucl. Eng. Des. 334, 75-89. https://doi.org/10.1016/J NUCENGDES.2018.05.001.

Chiang, Y., Chen, S.-W., Wang, J.-R., Wang, T.-Y., Chen, H.-C., Hsu, W.-S., Chiang, S.-C., Shih, C., 2017. Code crosswalk of Fukushima-like simulations for Chinshan BWR/4 NPP using MELCOR2.1/SNAP, TRACE/SNAP, PCTRAN and MAAP5.03. Nucl. Eng. Des. 325, 12-24. https://doi.org/10.1016/J.NUCENGDES.2017.09.023. 
de la Rosa, J.C., Escrivá, A., Herranz, L.E., Cicero, T., Muñoz-Cobo, J.L., 2009. Review on condensation on the containment structures. Prog. Nucl. Energy. https://doi. org/10.1016/j.pnucene.2008.01.003.

Dominion, 2006. Gothic methodology for analyzing the response to postulated pipe ruptures inside containment. DOM-NAF-3-NP-A Topical Report Dom-NAF-3NP-A.

EPRI, 2016a. Gothic thermal hydraulics analysis package. Version 8.2 (QA) 2, 662.

EPRI, 2016b. Gothic thermal hydraulics analysis package. Qualification Report Version 8.2 (QA) 2, 662.

Estévez-Albuja, S., Jimenez, G., Al Issa, S., Macián-Juan, R., Fernández-Cosials, K., Queral, C., 2018. Steam condensation simulation in a scaled IRWST-ADS simulator with GOTHIC 8.1. Nucl. Eng. Des. 334, 96-109. https://doi.org/ 10.1016/j.nucengdes.2018.04.020.

Fernández-Cosials, K., Jimenez, G., Bocanegra, R., Queral, C., 2017. Study of hydrogen risk in a PWR-W containment during a SBO scenario; Tau parameter definition and application on venting strategy analysis. Nucl. Eng. Des. 325, 164-177. https://doi.org/10.1016/j.nucengdes.2017.10.012.

Fernández-Cosials, K., Jiménez, G., Serrano, C., Ibáñez, L., Peinado, Á., 2018. Analysis of inertization strategies for the filtered containment venting system in cofrentes nuclear power plant. J. Nucl. Eng. Rad. Sci. 4,. https://doi.org/ 10.1115/1.4038595 031016.

Fernandez-Moguel, L., Birchley, J., 2015. Analysis of the accident in the Fukushima Daiichi nuclear power station Unit 3 with MELCOR 2.1. Ann. Nucl. Energy 83, 193-215. https://doi.org/10.1016/J.ANUCENE.2015.04.021.

Gallego-Marcos, I., Kudinov, P., Villanueva, W., Kapulla, R., Paranjape, S., Paladino, D., Laine, J., Puustinen, M., Räsänen, A., Pyy, L., Kotro, E., 2018. Pool stratification and mixing induced by steam injection through spargers: analysis of the PPOOLEX and PANDA experiments. Nucl. Eng. Des. 337, 300-316. https://doi org/10.1016/J.NUCENGDES.2018.07.004.

Hansen, G., Owen, S., 2008. Mesh generation technology for nuclear reactor simulation; barriers and opportunities. Nucl. Eng. Des. 238, 2590-2605. https:// doi.org/10.1016/j.nucengdes.2008.05.016.

Hargroves, D.W., Metcalfe, L.J., Wheat, L.L., Niederauer, G.F., Obenchain, C.F., 1979. Contempt-LT: a computer program for predicting containment pressuretemperature response to a loss-of-coolant accident.

Hong, S.J., Choo, Y.J., Hwang, S.H., Lee, B.C., Ha, S.J., 2015. Development of CAP code for nuclear power plant containment: Lumped model. Nucl. Eng. Des. 291, 4763. https://doi.org/10.1016/J.NUCENGDES.2015.04.034.

Hultgren, A., Gallego-Marcos, I., Villanueva, W., Kudinov, P., 2014. Large Scale Erosion of a Helium Stratified Layer by a Vertical Jet Using the GOTHIC Code (NUTHOS10-1290). NUTHOS10. AESJ, Okinawa, Japan, pp. 1-18.

Jimenez, G., Fernández-Cosials, M.K., Bocanegra, R., Queral, C., 2017. Analysis of the equipment and instrumentation qualification criteria using 3D containment models. Nucl. Eng. Des. 323, 28-38. https://doi.org/10.1016/j. nucengdes.2017.07.038.

Kim, J., Hong, S.-W., 2015. Analysis of hydrogen flame acceleration in APR1400 containment by coupling hydrogen distribution and combustion analysis codes. Prog. Nucl. Energy 78, 101-109. https://doi.org/10.1016/j. pnucene.2014.09.003.

Kim, J., Hong, S.-W., Kim, S.-B., Kim, H.D., Lee, U., Royl, P., Travis, J.R., 2004. 3 Dimensional analysis of the steam-hydrogen behavior from a small brak loss of coolant accident in the APR1400 containment. J. Korean Nucl. Soc. 36, 24-35.

Lopez-Alonso, E., Papini, D., Jimenez, G., 2017. Hydrogen distribution and Passive Autocatalytic Recombiner (PAR) mitigation in a PWR-KWU containment type. Ann. Nucl. Energy 109, 600-611. https://doi.org/10.1016/j.anucene. 2017.05.064.
Mesina, G.L., 2016. A History of RELAP Computer Codes. Nucl. Sci. Eng. 182, v-ix https://doi.org/10.13182/NSE16-A38253.

NEA/CSNI/R(2014)8 OECD/NEA, 2014. NEA/CSNI/R(2014)8. Status Report on Hydrogen Management and Related Computer Codes, NEA/CSNI/R(2014)8. OECD/NEA.

OECD/NEA, 2012. Oecd/Seth-2 Project Panda and Mistra Experiments Final Summary Report. NEA/CSNI/R(2012)5

Ofstun, R.P., Espinosa, R.J., Logan, C.P., Genuske, M.E., Lukas, R.B., 2013 Westinghouse Containment Analysis Methodology - PWR LOCA Mass and Energy Release Calculation Methodology, WCAP-17721-NP.

Ozdemir, O.E., George, T.L., Marshall, M.D., 2015. Fukushima Daiichi Unit 1 power plant containment analysis using GOTHIC. Ann. Nucl. Energy 85, 621-632. https://doi.org/10.1016/j.anucene.2015.06.017.

Paladino, D., Zboray, R., Andreani, M., Dreier, J., 2010. Flow transport and mixing induced by horizontal jets impinging on a vertical wall of the multicompartment PANDA facility. Nucl. Eng. Des. 240, 2054-2065. https://doi.org/ 10.1016/j.nucengdes.2010.03.036.

Papini, D., Andreani, M., Niceno, B., Prasser, H.-M., 2017. Evaluation of the Hydrogen Risk in Containment for Small Break Loca Sequences Using the GOTHIC Code. NURETH-17. ANS, Xian, China.

Papini, D., Steiner, P., Andreani, M., Nič, B., Klügel, J., Prasser, H., 2015. Simulation of the hydrogen distribution in a power plant using the GOTHIC code. ERMSAR2015. SARNET, Marseille, France, pp. 24-26.

Prabhudharwadkar, D.M., Iyer, K.N., Mohan, N., Bajaj, S.S., Markandeya, S.G., 2011. Simulation of hydrogen distribution in an Indian Nuclear Reactor Containment. Nucl. Eng. Des. 241, 832-842. https://doi.org/10.1016/j.nucengdes.2010.11.012.

Royl, P., Rochholz, H., Breitung, W., Travis, J.R., Necker, G., 2000. Analysis of steam and hydrogen distributions with PAR mitigation in NPP containments. Nucl. Eng. Des. 202, 231-248. https://doi.org/10.1016/S0029-5493(00)00332-0.

Ruiz-Zapatero, M., Bocanegra, R., Jimenez, G., Queral, C., 2016. Modelo detallado para un diseño estandar PWR-W con el codigo MELCOR 2.1. 42 Reunión Anual SNE. SNE, Santander, Spain.

Šadek, S., Grgić, D., Šimić, Z., 2017. Application of ASTEC, MELCOR, and MAAP Computer Codes for Thermal Hydraulic Analysis of a PWR Containment Equipped with the PCFV and PAR Systems. Sci. Technol. Nucl. Install. 2017. https://doi.org/10.1155/2017/8431934.

Wang, Y., Yang, Y., 2017. Study on containment pressure response with passive containment cooling system performance under design basis accident. Prog. Nucl. Energy 94, 22-35. https://doi.org/10.1016/j.pnucene.2016.10.002.

Xiao, J., Breitung, W., Kuznetsov, M., Zhang, H., Travis, J.R., Redlinger, R., Jordan, T. 2017. GASFLOW-MPI: A new 3-D parallel all-speed CFD code for turbulent dispersion and combustion simulations: Part I: Models, verification and validation. Int. J. Hydrogen Energy 42, 8346-8368. https://doi.org/10.1016/j. ijhydene.2017.01.215.

Xiao, J., Travis, J.R., Royl, P., Necker, G., Svishchev, A., Jordan, T., 2016. Threedimensional all-speed CFD code for safety analysis of nuclear reactor containment: Status of GASFLOW parallelization, model development, validation and application. Nucl. Eng. Des. 301, 290-310. https://doi.org/ 10.1016/j.nucengdes.2015.12.033.

Yildiz, M.A., Yang, S.R., Vaghetto, R., Hassan, Y.A., 2018. Numerical analysis of $1 / 28$ scaled NGNP HTGR reactor building test facility response to depressurization event using GOTHIC. Ann. Nucl. Energy 119, 46-65. https://doi.org/10.1016/J. ANUCENE.2018.04.030.

Yu, F., Zhang, H., Li, Y., Xiao, J., Class, A., Jordan, T., 2018. Voxelization-based highefficiency mesh generation method for parallel CFD code GASFLOW-MPI. Ann. Nucl. Energy 117, 277-289. https://doi.org/10.1016/j.anucene.2018.03.045. 